\title{
The Discovery of the Traits of Gifted and Talented Students in ICT
}

\author{
Mazalah Ahmad $^{1}$, Jamaluddin Badusah ${ }^{1}$, Ahmad Zamri Mansor ${ }^{1} \&$ Aidah Abdul Karim ${ }^{1}$ \\ ${ }^{1}$ Faculty of Education, Universiti Kebangsaan Malaysia, Malaysia \\ Correspondence: Mazalah Ahmad, Faculty of Education, Universiti Kebangsaan Malaysia, 43600 UKM Bangi, \\ Selangor, Malaysia. Tel: 603-8921-6231. E-mail: mazalahahmad@yahoo.com
}

Received: July 22, 2014 Accepted: November 5, 2014 Online Published: December 21, 2014

doi:10.5539/ies.v7n13p92 URL: http://dx.doi.org/10.5539/ies.v7n13p92

\begin{abstract}
This study discovers talent development among the individuals who are gifted and talented in Information and Communications Technologies (ICT). Using qualitative research methods, data was gathered via interview sessions with three groups of respondents who have excelled in the field of ICT, namely the academicians in ICT, the practitioners, and the students who have exhibited their intelligence in ICT. The data was analyzed and structured based on Gagne Differentiated Model of Gifted and Talent (DMGT). Based on DMGT, the data was categorized to natural abilities, interpersonal catalyst, and environmental catalyst. The findings of the study discussed the pattern of talent development among the gifted and talented individuals in ICT from the aspects of life background, educational background, education and experience in ICT, and the support factors towards talent development. The findings of the study indicated that gifted and talented individuals in ICT should be recognized as a unique talent at par with the other fields regarding the context of gifted and talented. Schools should provide the assessment methods as well as the sources to identify and develop the potential of another group of extraordinary individuals in the $21^{\text {st }}$ century.
\end{abstract}

Keywords: ICT gifted, ICT talent, Gagne Differentiated Model of Gifted and Talent (DMGT), computer technology talent

\section{Introduction}

Students nowadays have been exposed to the usage of technology since their early childhood (Wilkinson, 2006). Therefore, they have become utterly skilled in technology when they reach their adolescence years, and their fascination towards technology has become normality (Cross, 2005). Thus, it is not impossible that among the students in school, a group of students who can be regarded as gifted and talented in ICT may possibly exist. However, in schools, ICT tend to be utilized as the support material in the teaching and learning of other subjects such as Science, Language or Communication, and it is not regarded as a specific field (O'Brien et al., 2005). The failure of the school to identify the gifted and talented students in ICT, as well as to provide specific course which focuses on the development of their talents will lead to a number of negative consequences towards the economy of the nation (Cakeda, 2007). For example, in the United States of America, companies related to computer technology strive to look for talented individuals to fill in the vacancy. The positions, among all require knowledge in information technology. In order to deal with it, USA government has decided to reduce the limit on visa to enable workforces from all over the world to fill in the vacancies which require high skills (Cekeda, 2007).

Drastic increase towards the usage of technology in the community nowadays leads to an all-day access to computers to majority of the students. Since the 1980s, the access to computer, Internet and other digital technologies in schools and residence has been increasing drastically, and the percentage is continuously rising up to the present day. This phenomenon has created the difference in terms of students' ability to use and integrate ICT in their lives. The difference of students' ability should be identified and specific adaptation need to be implemented for the students with extraordinary ability. It is proven by previous research that without challenging surroundings, a lot of students with intellectual talents can be bored hence losing their interest towards the subject they learn about (Winner, 1996). The findings from this study can be used as the reference as to assume that the same possibility will occur to the students with talents and intelligence in ICT. According to Siegel (2004), the identification of the gifted and talented students in ICT need to be formally implemented, as the first step in developing any talent is to identify the talent owned by the individuals. 
In Malaysian context, the policy of ICT in education stated in Pelan Induk Pendidikan 2001-2010 (Malaysia Education Blueprint 2001-2010) has the objective to produce students who are not merely the users of ICT but are also able to create innovation (KPM, 2006). This objective is further developed through Pelan Induk Pendidikan Malaysia 2013-2025 (Malaysia Education Blueprint 2013-2025) which stated that KPM will discover the specific solution for the niche intervention groups such as the talented learners (KPM, 2012). In achieving this, schools need to not only prepare the students to be effective ICT users, but also acknowledge those with extraordinary abilities in ICT. Moreover, schools should play the role to recognize and develop the talents of the students with outstanding ICT abilities. The nation needs the skills owned by the gifted and talented students in ICT to enhance the nation's economic development, while the educators have the responsibility to identify the gifted and talented students in ICT hence supporting them in developing and maximizing their talents and intelligence.

Until recently, a lot of studies have been implemented to measure the level of knowledge and skills among the students in using ICT (Hardy et al., 2005; Wilkinson, 2006; Rosidayu, 2006; Megatet al., 2007; Hullick \& Valentine, 2008; Morris, 2010). However, studies on how students develop their talents and skills in ICT are still lacking. Studies related to personal quality and required surrounding to develop the potential of talented students have been vastly implemented among the gifted and talented students in the field of Music, Mathematics and Language among others. Nonetheless, there is still very little research focusing on the development of the gifted and talented students in ICT, specifically in Malaysian context. Natural ability and talent in ICT within the students should be identified as soon as possible, so the talent could be stimulated and fueled up hence the students can finally be shaped into being a contributing human capital towards the development of the nation. Thus, this study is implemented to discover the pattern of formative experience, cognitive ability and personality traits which can be labeled as those of gifted and talented students in ICT. This study discovers the factors contributing to the individual talent development in ICT. Furthermore, this study assesses on how individual personality and required surrounding are related in developing ICT talent. This study is constructed to enable the gifted and talented individuals in ICT to explain the process of the development of their talents in ICT using their own words.

\section{Purpose of the Study}

Individual intelligence and talent is constructed on the basis of positive perception towards ICT and the desire to continuously discover the computer system and later generate new ideas beyond normal people scope. These extraordinary individuals are able to nurture their talents in the field of ICT technology and have the potential to succeed by the means of their talents (O'Brien, 2007). This study is implemented with the intention to identify the personal characteristics and life experience affecting the individual ICT talent development. Apart from that, this study intends to identify the factors affecting the development of talent among the gifted individuals in ICT.

Information regarding intellectual and personal quality of the gifted individuals in ICT is needed to ease the process of students' talent development in ICT by the means of teaching and learning activities as well as the activities outside of the classroom. The findings from the study can be used as the guideline to the teachers and parents regarding the ways to develop the talents of students identified as talented in ICT. In addition, the findings can also be used in designing specific curriculum for the gifted and talented students in ICT, thus the curriculum will be able to challenge their abilities up to the level that can make them as creators of innovation.

\section{Theoretical Framework}

This study is implemented based on Gagne Differentiated Model of Gifted and Talent (DGMT) to discover the life of individuals whom have been identified as possessing intelligence and talent in ICT. Gagne has implemented the studies related to the process of talent development among the individuals recognized as gifted and talented. According to Gagne (2004), the process of individual talent development take into account the factors such as individual's natural abilities, environment catalyst, and intrapersonal catalyst. Natural abilities are determined by the individual's mental and physical capability, while intrapersonal catalyst is perceived from the aspects of traits and goal-management. On top of that, environment catalysts cover the aspects of milieu, individuals, and provisions.

\subsection{Natural Abilities}

Mental ability under natural abilities is determined by four elements, namely intellectual, creative, social, and perceptual. Intellectual abilities cover general intelligence, fluid, crystallize reasoning verbal, numerical, spatial memory, procedural and declarative (Gagne, 2009). The most important intellectual abilities for a gifted and talented individual in ICT are the problem-solving ability and logical thinking (O’Brien, 2007). 
Creative thinking is also an important aspect in natural abilities. The study by Saunders and Thagard (2005) found that in Science Computer, creative thinking is applied during programming and problem solving. Creative thinking is displayed via scribbling, doodling, brainstorming, experimenting and having animated conversation with peers about problem while trying to solve technology problem.

From the aspect of social abilities, projects in Computer Science usually need creative problem solver. Pertaining to the effort of expanding their talents, gifted individuals in ICT have to abandon their social interaction (O’Brien, 2007). This statement verifies the claim by Holland and Austin (1962) which stated that individuals involved in creative works are usually labeled as those who socialize less.

\subsection{Intrapersonal Catalyst}

Aside from natural abilities, individual talent development is also influenced by intrapersonal catalyst. The combination of mental and physical characteristics alongside the elements in goal-management such as awareness, motivation and volition is believed to have effect on the process of the development of talents for the gifted and talented individuals.

The aspect of awareness covers talented individual's quality such as their strength and weaknesses. Talented students with high level of self-management and self-regulation are able to plan the steps required in achieving their objectives and have the confidence that they will be able to solve the problem given to them. In ICT, a programmer is able to learn a new program all by himself. When a program is not functioning the way it is wanted to be, a programmer do not need to ask for help from other person in order to deal with it (Gagne, 1999).

Another important catalyst of talent development in interpersonal catalyst is motivation. Students with extraordinary talents usually possess very high level of motivation to instantly achieve the desired objective (Machlowitz, 1985). Challenges and external factors can help in improving their extrinsic and intrinsic motivation to improve their ICT knowledge and skills (O'Brien, 2007).

Volition is one of the catalysts in interpersonal catalyst. According to Gagne (2009), volition covers autonomy, effort and perseverance. In achieving an objective, a student will not only need motivation, but he will also need to continuously strive to be successful. The field of Computer Science is indeed very challenging, and almost always will require sacrifice in terms of time and energy. However, in cases of individuals like Bill Gates and Steve Jobs, their sacrifices are worthy as to compare with the success of their companies (Landrum, 1993).

\subsection{Environment Catalyst}

Another important element in the talent development of gifted and talented individuals is environment catalyst. Environmental factors such as culture, human and sources are the factors with important roles in the development of individual talent (Gagne, 2009).

It is agreed by a lot of theories that family is the environmental factor with the strongest influence towards individual talents (Gowan et al., 1979; Winner, 1996). On the other hand, peers also give a significant impact towards the development of student's talent (Schneider, 1987). Students with their own computer prefer to explore certain software, surf the Internet, share their ideas, and cooperate in project works with their friends. They are usually able to befriend other students with the same interest as well as the level of ICT skills (O'Brien, 2007).

School also plays an important role in talent development (Freeman, 2000; Gallagher, 2003). Gifted and talented students will get the benefit from the formal education system if the teachers are ready to educate themselves about the excitement and the benefit from the usage of computer in teaching and learning, and they are ready to use computers in the classroom (O'Brien, 2007).

Natural ability and interpersonal traits of an individual supported by the stimulating environmental factors will produce a systematic talent development. However, this theory in not a guarantee as the hypothesis suggested by Gagne (2004) stated that only 10 percent from the top group of talented individuals managed to make use of their talents in certain fields. Other than the combination of individual traits and experience, there is the factor of 'coincidence' which eventually will affect the individual talent development if that person happens to be at the right place and time. Considering the experience that the gifted and talented students in ICT have had, the process of their talent development will be better understood. Guided with the factors stated in DMGT, this study will acquire the information that will be helpful to the deeper understanding regarding the talent development of the gifted and talented individuals in ICT.

\section{Method}

This study is a qualitative study with the objective of exploring personal background, experience and the talent 
development process of the individuals identified as gifted and talented in ICT. Interview session with the participants of this study is implemented to obtain the information related to the experiences of those talented in ICT, from the aspects of cognitive and affective such as capability, aptitude and behavior which influence them to be deeply interested in ICT.

Purposive sampling is employed in this study. The participants of the study were selected among the individuals with vast experience, highly knowledgeable and skilled in ICT, and have great interest in ICT. The selected participants are those who agreed and interested to voluntarily participate in this study.

The participants of this study consist of academicians $(\mathrm{N}=6$, Male=2, Female=4) in the field of ICT from local higher learning institutions. These six academicians were selected as participants in this study due to their ICT-related experience, their skills and knowledge of ICT and deep interest in ICT. They are not only choose to be professional in ICT area but they also gained success in their career once they are appointed as heads of departments in the Faculty of Information Science and Technology. They are between 35 to 45 years old.

Five information technology officers (Male=3, Female=2) were also selected as participants of the study. Their age between 35 to 45 years. They were selected based on their active involvement in the maintenance of ICT facilities in their work place. They are expected having extensive experience in ICT, high skills and knowledge of ICT, talented in ICT and also having deep interest in ICT. Thus, the researchers hope that these selected practitioners are able to give all information needed to answer the research questions

Six university's students (Male=3, Female $=3$ ) were selected to participate in this study. Their age between 20 to 25 years. These students are studying at Faculty of Information Science and Technology in the local university. They were identified by their lecturers as students who have great talent and a deep interest in the field of ICT. These students have been selected as participants in this study due to recommendation of their lecturers.

For the purpose of this study, in-depth interviews were implemented to enable the researcher to collect the data from the participants. Structured interview protocol was utilized during the interview sessions and the conversation between the researcher and the participants were recorded using auto digital device. As soon as each interview session ended, the conversation would be transcribed by the researcher to produce the interview verbatim. Reduced verbatim from the interview was inductively analysed.

A pilot study was conducted to test the usability of interview protocols developed by the researcher. In this pilot study, one participant had been selected to represent each group of participant. The respondents involved in this pilot study were named as Expert1, Expert2 and Expert3.

Expert1 is an academician in Faculty of Technology and Information Science in a local higher education institution, and he possesses a Doctorate degree from abroad university. He is 42 years old and he has served as a lecturer at the university for 15 years. Expert2 is a practitioner with working experience in four ICT-related firms and currently working as a system engineer. He is 35 years old. He attained a Bachelor's Degree in Computer Science from a local higher learning institution.

On top of that, Expert3 is a student from the Faculty of Technology and Information Science in a public higher learning institution. He is a second year student majoring in Multimedia Studies. He is 23 years old. He was chosen as the respondent as he has managed to manipulate ICT technology to promote a national level program. In addition, he has also produced a database system for the usage of Al-Quran club. The project is able to record the members' data as well updating the recitation done by each member.

\section{Research Findings and Discussion}

This paper only reports on the data acquired from pilot study. The Data from the findings was analyzed and structured based on the components available in Gagne's (2009) Differentiated Model of Gifted and Talent (DMGT) namely Natural Abilities, Intrapersonal Catalyst and Environment Catalyst, and finally Development Process.

\subsection{Natural Abilities}

DMGT proposed four ability domains for Natural Abilities; intellectual, creative, social and perceptual. Each domain can be divided into several categories,

\subsubsection{Intellectual}

According to Gagne (2009), a student may be categorized as gifted students in a particular field when students excellent in a particular subject. Talented individuals built from continuous learning process by students who are gifted. In this study, these three respondents interviewed have excellent educational background. 
In school, Expert1 was science students and studied at government's boarding schools. He obtained excellent results in the Malaysian Certificate of Education Examination. He then continued his studies in ICT area, and got his diploma and Bachelor degree in Computer Science and Computer security. As a lecturer at a local university, Expert1 has obtained a government scholarship to pursue his study for Master degree at London and $\mathrm{PhD}$ degree at Manchester. Expert1 got his Master degree in Information Security and $\mathrm{PhD}$ degree in Informatics.

Similar to Expert1, Expert2 was science student too, and was studied at MARA Junior Science College. He also obtained excelled results in the Malaysian Certificate of Education and later obtained a Bachelor's Degree in Computer Science from the local university.

On top of that, Expert3 was students in regular school. After obtaining excellent results in the Malaysian Certificate of Education, he is currently studying at a local university, majoring in Multimedia Studies. While in school, Expert3 joined a robotics workshop at the national level. In the age of 23 years, has managed to build a system for registration and database of reading Koran. Expert3 also been appointed as Assistant Director of Projects that use multimedia to promote student program at the national level.

The ability of all three respondents in ICT really surfaced out when they were given the responsibilities to further their studies to the higher level of education in ICT and also handling major ICT projects. Expert1 received his scholarship to further his Master's Degree studies in Information in Security and his Doctorate Degree in Informatics. Expert1 describes his PhD studies, "in my PhD studies, I designed trust model... in the aspect on how we want to evaluate 'the trustiness' in online base system, where it is more to calculating". As an academician, Expert1 has also obtained research grant from the community and industry to develop software. Aside from that, Expert2 has experiences in working with four companies where most of them are related to ICT. He was and still is involved in system development projects related to quality control, packaging, "bug tracker system" and others according to customers' demand. On top of that, Expert3 is the project leader for the KRQ system. KRQ system is a database system for the registration of the Al-Quran club members as well as updating the recitation of each member. Other than that, Expert3 has also managed to utilize ICT in an effort to promote a national level mega program known as "Ekspresi Mahasiswa13".

\subsubsection{Creative}

Creative can be separated into two different concepts, such as creation in something completely novel, or the recombination of olds ideas into something new (Feldman et. al., 1994). Creative thinking of Expert2 surfaced up while he was still in primary school. "When I was in standard six, I made a hovercraft model, yacht and land-mower using used materials. I managed to win the first prize for the yacht model in the invention competition for Living Skills subject" (Expert2). Expert3's creative thinking has enabled him to manipulate multimedia technology and succeed in promoting "Ekspresi Mahasiswa13" program in the national level.

The ability to generate idea and solve problem with technology requires creative thinking (O'Brien, 2007). With the creative thinking clearly evident among all three respondents, they have been directly involved with the development of system software. The system software developed must be in accordance with the customer's demand. Thus, the tasks and responsibilities of all three respondents indeed require individuals with a significantly high level of creative thinking ability.

Logical thinking skills and problem thinking skills are really needed to succeed in ICT. According to Expert1, "I became aware of my ability during my diploma studies... When I was studying in programming language... Most programming requires logic... In programming, it really needs logic... Most of my friends were not able to understand it, but I can...".Furthermore, as stated by Expert2, "I have the ability to analyze and logical thinking... The problem solving skills that I have are really useful for me to design the system according to the request made by the customer who will use it". Expert2 added, "...To be a good 'techie', someone needs to have problem solving skills, critical and creative thinking skills, analytical skills, cooperation and communication skills, and always need to be up-to-date with the current development in information technology."

\subsubsection{Social}

Person's ability to communicate with others and perceive social cues and action falls under socio affective (Gagne, 2004). In accordance with Gagne's statement, other than intellect and creative, all three respondents are also sociable. All three of them love to help others especially when it is related to ICT. According to Expert2, "I love to help those who have problems with computers because I believe that the reason God gives me this ability is to help others..." Expert3, on the other hand justified "I will try my very best to help the college and my friends who have problems related to ICT". When Expert1 was asked; "Do you like to help people with computer problems?" he replied, "Yes, because I know and I am expert in this field". 
In implementing the task given to them, all three respondents were observed to be more comfortable working in a group rather than on their own. As Expert3 said, working in group allows the work pressure to be felt together.

\subsection{Intrapersonal Catalyst}

The intrapersonal catalyst has five sub-components grouped into two main dimensions, namely stable traits (physical or mental) and goal management processes (self-awareness, motivation, and volition) (Gagne, 2010). However, this study only includes the discussion on the aspect of goal management process.

\subsubsection{Awareness}

Awareness involves any process which has the influence on the development of the self-concept and self-esteem (Gardner, 1983). In this study, the answers from all three respondents stated that they are highly confident and friendly. Other traits are positive thinking (Expert1), cheerful (Expert2); love to try something new (Expert2) and active in sports (Expert3).

\subsubsection{Motivation}

Motivation plays an important role in the process of an individual talent development. Factors such as needs, value, interest and objectives are needed to master any certain field. There are two motivation values that help the individual to achieve success, namely intrinsic and extrinsic motivation. Intrinsic motivation refers to the motivation that comes from within an individual. It comes from the excitement and the satisfaction achieved after completing a task. Individuals with intrinsic motivation will work because of the excitement coming from the completion of a problem or task and dealing with the challenges, and not because of the reward. Extrinsic motivation is the motivation coming from outside of the individuals. This type of motivation includes all kinds of reward such as praise, grades, special privileges, prizes, money, attention from adults, or admiration from peers.

Necessities are the elements needed for an individual to gain motivation. "Successful feeling" is needed to create intrinsic motivation within an individual. Indeed, praises on the work nicely done will be very exciting. Individuals, especially students, need praises and rewards to obtain extrinsic motivation. Praises and rewards are very effective in creating individual eagerness to complete a task given successfully.

Intrinsic motivation is needed to drive the students to use their own potential and achieving satisfaction as well as excitement from the activities that they do. All three respondents have exceptionally high intrinsic motivation. Such motivations within these individuals are highlighted with statements such as "...we can't give up" (Expert1); "I study hard and take whatever opportunity available..." (Expert1); "I didn't attend any computer class, I explore and learn everything by myself" (Expert2); "I think ICT is something very important in this era" (Expert3), and my biggest achievement is to successfully publicize a national level mega program, which is "Ekspresi Mahasiswa13" (Expert3).

Other than having intrinsic motivation, their successes were also driven by extrinsic motivation such as "I was offered quite a number of scholarships; I received federal scholarship for my degree studies, excellent student scheme for my masters study and as for my PhD I received Commonwealth scholarship" (Expert1), "I won first place for the yacht model in the invention competition for the subject of Living Skills" (Expert2) and "I as the leader of this project was given the responsibility by the lecturer to develop KRQ system" (Expert3).

From the aspect of interest, respondents have great interest in ICT. The interest has already existed since the childhood years for some of the respondents. As said by Expert2, "When I was in standard six, I have constructed models of hovercraft, yacht and lawn-mower using used materials."

Great interest towards ICT has driven the respondents to really strive in trying. Their determination was noted with their statements such as "When I'm facing any problem in completing a task, usually I will straight away ask the supervisor, find the solution on the Internet and always exploring possibilities". "Efficiency must be maintained" (Expert2) and "I will try as hard as I can to help the college and my friends who have any ICT problem" (Expert3).

Their interest towards ICT has also led the respondents to always strive and make efforts to improve their knowledge and skills. "I learned about ICT by exploring it myself" (Expert2), "I always search for new things to be applied in system development" (Expert2), "In order to make sure that my knowledge and skills in ICT are at par with the technology growth... I always surf the Internet especially websites like Youtube" (Expert3), "I learn a lot from Google and YouTube" (Expert3). "I was involved in the robotic association at my school and once participated in the national level robotic workshop... these activities develop my interest" (Expert3).

Furthermore, the respondents are willing to make use of the knowledge and skills regardless of when they need 
to do so. "I will try my best to help the college and my friends who have problems related to ICT" (Expert3) and "Always help others in computer-related matters even it is outside of office hour" (Expert2).

Among the respondents, Expert3 has a very clear objective, which is "to start an editing company and an advertising shop specially operating for education institutions", while Expert1 and Expert2 did not state any objective to be achieved in the context of their career.

\subsubsection{Volition}

Intrinsic and extrinsic motivation, great interest and clear objectives made the respondents of this study as determined and persistent individuals. Their strong willpower can be observed from their statements such as " $I$ study very hard and take whatever opportunities available" (Expert1), "Yes, we should not give up" (Expert1), "I learn about ICT by my own exploration. Thus, I always make use of my energy in learning ICT, for instance sleeping very late at night" (Expert2), "Technology keeps on changing... we have to always learn new things as ICT is constantly developing" (Expert2) and "I will try my best to help the college and my friends who have problems related to ICT" (Expert3).

\subsection{Environment Catalyst}

Environment catalysts consist of three different sub-components, namely mileu, individuals and provisions (Gagne, 2010).

\subsubsection{Milieu}

The first sub-component in environment catalyst is milieu. It includes various environmental influences such as physical and geographical properties (e.g.: climate, urban vs. rural lifestyle), social, culture or family. The respondents admitted that their family members and friends have been very supportive towards their positive achievements in ICT. For instance Expert1 is truly moved by the sacrifice of his wife who is willing to re-sit for an examination overseas for her to enable herself to further her study in the same country where Expert1 was studying. According to Expert2, "My wife always support me so that I won't give up in solving certain problems and has always been very compassionate and concerned towards me so I can continuously develop myself in this field" (Expert2).

\subsubsection{Individuals}

The second sub-component in environment catalysts focuses on the influence of individuals which is crucial in talent development. It can be consisting of parents, family, peers, teachers and mentor. As stated Expert3, family, teachers and friends are very supportive towards him. Nevertheless, his teacher's wisdom words are indeed very impactful towards Expert3's interest in ICT. According to him, hi teacher once said “...if these interest and talent are developed, it will give postive effects towards me and others too. Other than that, my friends have also given a lot of supports for me to produce even better materials and multimedia presentation" (Expert3).

Expert 1 and Expert2 have their own idols as their inspirations. Expert1 said that "I really admire innovative stuff... anyone who invents such as Steve Jobs and Bill Gates" (Expert1). Expert3, on the other hand has his keen admiration on Steve Jobs, as like he said, "He is a very persistent man who never give up even he was sacked from his own company. His determination in changing the world made him my idol" (Expert3).

\subsubsection{Provision}

The third sub-component covers all kinds of services and programs of talent development. It includes enrichment, curriculum, pedagogy (pacing), administrative, grouping and acceleration. Two respondents; Expert1 and Expert2 has gotten their exposure regarding computer since they are in their secondary schools as computer classes are provided to the students from Form 1 to Form 5. As for Expert3, regardless of the fact that his school did not provide specific computer class, computer labs usually held classes or basic workshop for general application such as Microsoft Office.

The interest of Expert3 towards computer has developed through the programs implemented by the school such as the British Council program - short essay, and Robotic Lego Mindstorm. "These programs involved basic programming as well as creativity" (Expert3). "I was involved in the robotic association in my school and I went to the national robotic workshop in the year of 2009" (Expert3).

Other than that, communicative media is also accounted in promoting the development of ICT knowledge and skills among the respondents. "I learn a lot from Google and YouTube. In YouTube, there are a lot of tutorials to help us in understanding certain matter". (Expert3). "When I'm facing some problems upon completing a task, I will usually straight away ask my supervisor, looking for the solution on the Internet, and continuously exploring possibilities" (Expert2). 
The rewards obtained by Expert2 in the invention world have driven him to continuously come up with more creations in ICT. "I won the first place for the yacht model in the invention competition for the Living Skills subject" (Expert2). As compared to Expert3, the sense of accomplishment in promoting a national-level mega program which is "Ekspresi Mahasiswa 13" has driven Expert3 to continuously achieving more successful accomplishments. Other than that, Expert3's interest towards ICT started to grow because of his favorite animation series. "I am very interested in the animation "Kluangman" which used $3 D$ animation at that time, and it really interest me to find out and know more about ICT" (Expert3).

\subsection{Other Findings}

Other than the elements listed under DGMT, the researcher also intend to find out whether religion has its own role towards the achievement of the gifted and talented individuals in ICT. Human capitals needed are those who have firm religious belief henceforth possessing knowledge and skills in professional field. With the good traits of a believer an individual will incidentally possesses good values such as integrity, diligent, honest, responsible, and much more (Pahrol, 2010).

From the spiritual aspect, Expert2 and Expert2 have very high conviction that their success in ICT is not merely because of their efforts but also the guidance and help from the Almighty God. This credence is surfaced through their statements such as stated below;

"I received a lot of scholarships. For my bachelor's degree I received federal scholarship, and as for my master's degree I managed to get the scholarship from MARA excellent student scheme (Skim Pelajar Cemerlang MARA). For my PhD I received Commonwealth Scholarship... These are all the rezeki from Allah..." (Expert1).

"Actually... each and everything that I got is the rezeki from the Almighty God... If I were to say that these are all my effort alone... there are a lot of others who have more efforts than me, but they did not manage to get it. So, for me these are all more to the rezeki actually. Whatever it is that I have is actually the one that He gave to me" (Expert1).

"We have to believe in ourselves, strive hard, and study really hard to achieve something. Most importantly, we have to put continuous efforts, and have firm belief toward the Almighty God" (Expert1).

When questioned whether prayers contribute to their success, the respondents replied "I believe that success is the result of your prayers, my parents', as well as others around me" (Expert1). I believe that prayer is one of the best weapons to achieve success especially the prayers from parents. After the efforts that we have, prayer is the successive step (Expert2).

Religious values also caused the respondents to have positive attitudes towards their studies and careers. According to them, "learning is jihad" (Expert2) and "I believe that working is an ibadah and later an even reward will be given equivalent to the contribution that I have given" (Expert2). Other than that, being helpful is also driven by religious conscience such as "I love to help other people facing computer problems because I do believe that one of the reasons that God bestow this ability upon me is to help other people. If I help others, God will help me later in any other way possible" (Expert2).

Students' excellence should be evaluated in three factors, namely knowledge, skills, and attitude (Pahrol, 2010). A merely excellent student in any field is unworthy and meaningless if he does not have good attitude and moral. Currently, a lot of people 'excel' in academic and economy but failed in family institution and living, involved in crime, full of regret and discontent, and many more negative matters. For that reason, to be an intelligent individual in ICT with good morals, that certain someone need to not only strive to gain more ICT knowledge and skills, but also be hardworking and continuously gain religious knowledge.

\section{Conclusion}

This qualitative study is a preliminary study to a larger study that is 'The Instrument Development of Identification of ICT Talented' for Malaysian Context. This study was conducted to explore the characteristics of ICT gifted. A pilot study was conducted to test the usability of the interview protocol developed by researchers for data collection in qualitative research. Therefore the findings reported in this article was merely sharing information about ICT gifted features and their experiences of those selected as participants in the pilot study. Thus, the findings discussed here is not a conclusion of qualitative research findings.

As in other fields, the abilities possessed by the gifted and talented students in ICT should be recognized and nurtured. This can be achieved by the supports from the experts in ICT as they can undeniably surpass the teachers when it comes to their expertise in this field. They can scaffold the students to obtain the skills as well as getting the needed equipment and devices to fulfill the curiosity among the students in generating new 
knowledge and skills.

The efforts in ICT talent development will not be able to be implemented if the ICT infrastructures available are not suitable. Up-to-date technology is needed to challenge students' ability hence fully develop their potential and talents in ICT. Thus, this will require cooperation from certain parties as to allow their gifted and talented students in ICT to use their highly advanced laboratories.

The technology in the future is a mystery. No one can really predict and let alone know about how it will be. Technology which seems to be utterly impossible in a few years back has become something very normal by now. Students with extraordinary talents in ICT today can possibly be the creators of ICT innovation in the future. Therefore, talents and intelligence in ICT among students should be identified and nurtured at once.

\section{References}

Bernstein, T. M. (1965). The careful writer: A modern guide to English usage (2nd ed.). New York, NY: Atheneum.

Cekada, J. F., Jr. (2007). A profile of students who display exceptional talent in computer technology. University of Pittsburgh). ProQuest Dissertations and These. Retrieved from http://search.proquest.com/docview /304822916? accountid $=41453$

Cross, T. L. (2005). Nerds and geeks: society's evolving stereotypes of our students with gift and talents. Gifted Child Today, 28(4), 26-27.

Feldman, D. H., Csikszentmihalyi, M., \& Gardner, H. (1994). Changing the world: a framework for the study of creativity. Westport, CT: Greenwood Press.

Freeman, J. (2000). Teaching for talent: Lesson for the research. In B. C. O’Brien (Ed.), Gifted geeks: The emergence and development of computer technology talent (p. 34). Available from ProQuest Dissertation \& Theses: Full Text (NR18185).

Gagne, F. (1999). Tracking talent: Identifying multiple talents through peer, teacher, and self-nomination. Waco, TX: Prifrock Press Inc.

Gagne, F. (2004). Transforming gifts into talents: DMGT as s developmental theory. High Ability Studies, 15(2), 121-147. http://dx.doi.org/10.1080/1359813042000314682

Gagne, F. (2009). Building gifts into talents: Brief overview of the DMGT 2.0. World Wide Web. Retrieved from http://nswagtc.org.au/images/stories/infocentre/dmgt_2.0_en_overview.pdf

Gagne, F. (2010). Motivation within the DMGT 2.0 framework. High Ability Studies, 21(2), 89-99. http://dx.doi.org/10.1080/13598139.2010.525341

Gallagher, J. J. (2003). Issues and challenges in the education of gifted students. In N. Colengelo, \& G. A. Davis (Eds.), Hanbooks of gifted education (3rd ed., pp. 11-23). Boston: Allyn \& Bacon.

Gardner, H. (1983). Frames of mind: The theory of multiple intelligences. New York: Basic Books.

Gowan, J. C., Khatena, J., \& Torrance, E. P. (1979). Educating the ablest: A book of reading on the educational of gifted children. Itasca IL:F.E.Peacock Publishers, Inc.

Hardy, C., Heeler, P., \& Brooks, D. (2005). Are high school graduates technologically ready for post-secondary education? Journal of Computing Sciences in Colleges, 21(4), 52-60.

Holland, J. L. \& Austin, A. W. (1962). The prediction of the academic, artistic, scientific, and social achievement of undergraduates of superior scholastic aptitude. Journal of Education Psychology, 53, 132-143.

Hulick, F. W., \& Valentine, D. (2008). Computer competency of incoming college students: Yet more bad news. The Proceedings of the Information Systems Education Conference 2008, 25, Phoenix. Retrieved from http://proc.isecon.org/2008/3134/ ISECON.2008.Hulick.pdf

KPM (Malaysian Ministry of Education). (2006). Malaysia Education Blueprint 2006-2010. 9th Malaysia Plan. Kuala Lumpur: Malaysian Government.

KPM (Malaysian Ministry of Education). (2012). Malaysia Education Blueprint 2013-2025. Malaysian Education Development Plan. Kuala Lumpur: Malaysian Government.

Landrum, G. N. (1993). Profiles of genius: Thirteen creative men who changed the world. Buffalo, NY: Prometheus Books.

Machlowitz, M. (1985). Whiz kids: Success at an early age. New York: Arbor House. 
Megat, A. Z. M. Z., Baharuddin, A., \& Jamaluddin, H. (2007). Kemahiran ICT di kalangan guru-guru pelatih UTM: Satu Tinjauan (A survey: ICT skills among UTM's pre-service teachers). Proceeding of The $1^{\text {st }}$ International Malaysian Educational Technology Convention (pp. 997-1002).

Morris, K. M. (2010). College and The Digital Generation: Assessing and Training Students for the Technological Demands of College by Exploring Relationships Between Computer Self-Efficacy and Computer Proficiency (Doctoral dissertation). Available from ProQuest Dissertation \& Theses: Full Text (NR18185).

O'Brien, B. (2007). Gifted geeks: The emergence and development of computer technology talent (Doctoral dissertation). Available from ProQuest Dissertation \& Theses: Full Text.

O’Brien, B., Friedman-Nimz, R., Lacey, J., \& Denson, D. (2005). From Bits and Bytes to C++ and Websites: What is Computer Talent Made of? Gifted Child Today, 28(3), 56-64.

Pahrol, M. J. (2010). Mukmin profesional (Muslim Profesional) (1st ed.). Malaysia: Selangor.

Rosidayu, S. (2006). Kefahaman dan kemahian ICT dalam kalangan pelajar-pelajar berpendidikan agama. Kertas kerja dalam Seminar Teknologi dan Sains. 29031 Mei. Kuantan.

Saunders, D., \& Thagard, P. (2005). Creativity in computer science. In B. C. O'Brien (Ed.), Gifted geeks: The emergence and development of computer technology talent (p. 26). Retrieved from ProQuest Dissertation \& Theses: Full Text

Schneider, B. H. (1987). The gifted child in peer group perspective. New York: Springer-Verlag New York, Inc.

Siegle, D. (2004). Identifying students with gifts and talents in technology. Gifted Child Today, 27(4), 30-33, 64.

Wilkinson, K. (2006). Students computer literacy: Perception versus reality. Delta Pi Epsilon Journal, 48(2), 108-120.

Winner, E. (1996). Gifted children: Myths and realities. New York: Basic Books.

\section{Copyrights}

Copyright for this article is retained by the author(s), with first publication rights granted to the journal.

This is an open-access article distributed under the terms and conditions of the Creative Commons Attribution license (http://creativecommons.org/licenses/by/3.0/). 